\title{
Development of Behavior Abnormalities in a Patient Prevented From Returning Home After Evacuation Following the Fukushima Nuclear Disaster: Case Report
}

\author{
Arinobu Hori, MD, PhD; Akihiko Ozaki, MD, PhD; Michio Murakami, PhD; \\ Masaharu Tsubokura, MD, PhD
}

\section{ABSTRACT}

After Japan's major nuclear accident in 2011, approximately 150,000 Fukushima residents were ordered to evacuate. Beginning in 2015 , the evacuation orders have been systematically lifted. However, the health impacts of allowing residents to return to homes in areas previously uninhabitable due to nuclear radiation remain poorly understood.

Declaring radiation levels to be safe does not necessarily eliminate the concerns of residents about the effects of radiation exposure. Rebuilding medical, welfare, and commercial infrastructure and services takes time. Nontangible community elements, such as mutually dependent social networks, also require time to be re-established. Nevertheless, the Japanese government prioritizes policies that encourage evacuees to return home as soon as it is safe to do so.

Post-disaster evacuation situations and subsequent return home pose substantial—and as yet relatively unknown-mental and physical health threats for those affected, especially those in vulnerable groups, such as the sick, the elderly, and children.

Here we report a case of an elderly female evacuee with dementia, who was prevented from returning home after her hometown evacuation order was lifted, began exhibiting marked behavioral abnormalities. Loss of emotional ties that were created while she was housed in temporary accommodation appeared to be a critical contributing factor.

Key Words: evacuation, evacuation order, nuclear disaster, Fukushima, temporary housing

I n March 2011, Japan's Fukushima prefecture experienced a triple disaster (major earthquake, tsunami, and nuclear accident at the Fukushima Daiichi Nuclear Power Station (FDNPS; Figure 1). Those who experienced the Great East Japan Earthquake (GEJE) and the subsequent unprecedented and catastrophic tsunami not only lost loved ones, homes, communities, infrastructure, and livelihoods, but they also experienced the resultant nuclear accident and radiation leak, which forced approximately 150,000 residents living near the FDNPS to be evacuated. ${ }^{1}$ Furthermore, subsequent frequent relocations disrupted the evacuees' newly established coping and social networks, which, coupled with continuing perceived radiation risks, adversely affected their mental health. ${ }^{2}$ Japan is already a "super-aged society," where well over $20 \%$ of the population is aged 65 years or older. Many of the Fukushima evacuees were elderly, with many suffering from declining physical and mental health. Although it is generally understood that returning home for these evacuees may improve their mental health, in this complex case of Fukushima, returnees generally encounter higher psychological distress upon returning home. ${ }^{3}$

The Fukushima evacuees were treated differently depending on the location of their original residence, with their evacuation status being either compulsory or voluntary. While the evacuation order was in effect, "compulsory" evacuees could rely on financial support for housing, medical care, and other essential services. On the other hand, once an evacuation order was lifted, many of those vital supports became unavailable for "voluntary" evacuees. ${ }^{4}$ Compensation payments varied according to the level of contamination of the property and other factors, with compulsory evacuees receiving monthly payments while voluntary evacuees received a onetime payment to support relocation expenses. This led to friction and disputes among evacuees, as well as with local residents who did not evacuate in neighboring areas. ${ }^{5}$ 


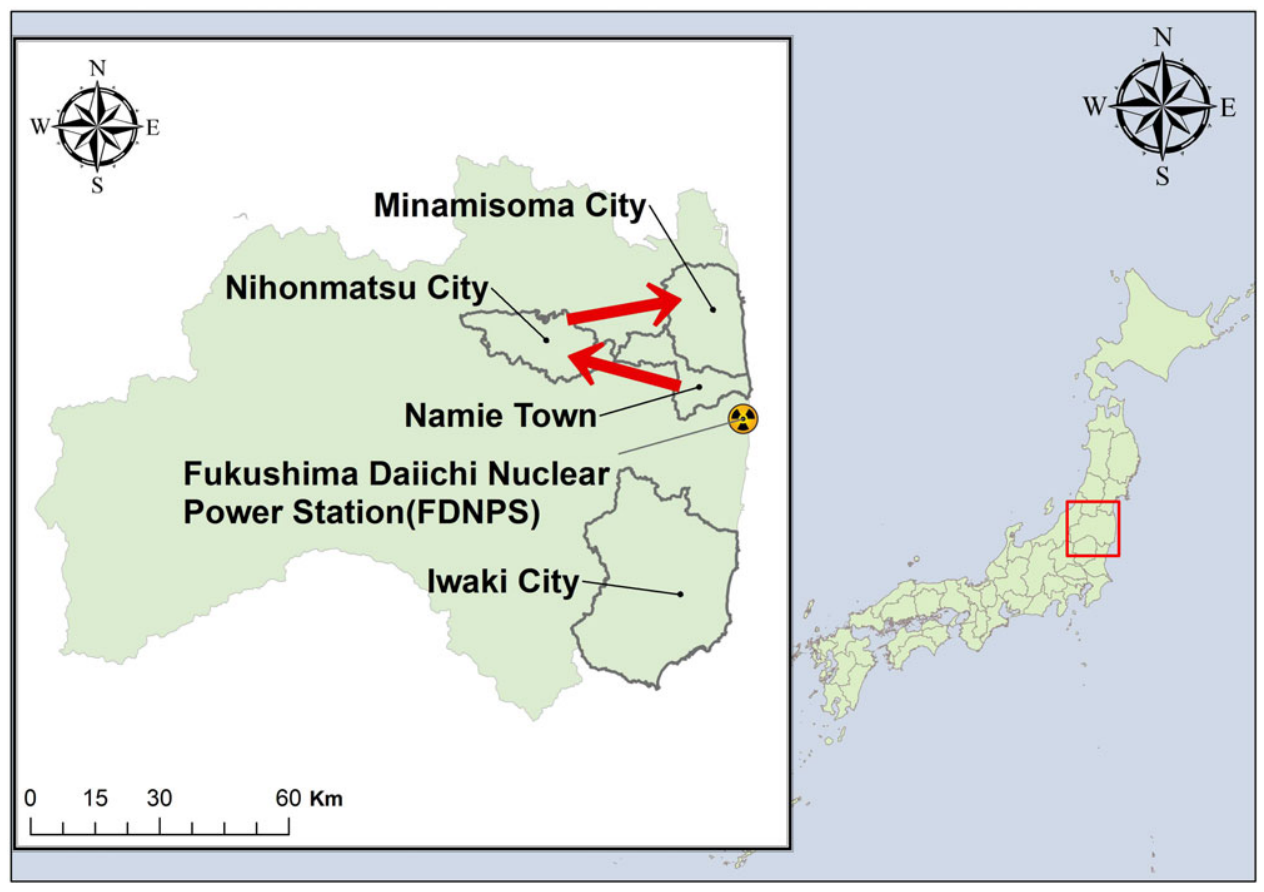

Namie Town: Patient's hometown until the disaster in 2011; Nihonmatsu City: Patient's residence August 2011 to March 2017; Minamisoma City: Patient's residence since March 2017; Iwaki City: Patient's son's residence.

Namie Town, a municipality near the FDNPS, was designated as a compulsory evacuation zone in 2011 with the evacuation order being lifted in March 2017. However, only 1189 people, out of the population of 21,000, had returned by December 2019. ${ }^{6}$

This is a report of an evacuee who showed notable behavioral abnormalities apparently connected to her inability to fulfill her wish to return home.

\section{Case (Narrative)}

The patient was an 80-year-old female, without notable past medical history, who was living in Namie Town with her husband and only son. After being forced to evacuate, she was regularly relocated to several shelters, and in August 2011, she was moved to temporary housing in Nihonmatsu City, $65 \mathrm{~km}$ from Namie Town. Her husband was hospitalized with pneumonia soon after the disaster and died in November 2011. Meanwhile, her son had started living and working in Iwaki City, around $60 \mathrm{~km}$ from Namie Town. While living alone in the temporary housing, the patient received comfort and support from her fellow evacuee neighbors. However, she gradually began to show outward signs of cognitive disability.

Following the lifting of the Namie Town evacuation order, the patient was forced to leave her temporary housing due to its closure. Despite a profound wish to return home, in April 2017, she moved to public housing in Minamisoma City, a municipality next to Namie Town. Residents from Minamisoma City generally received less financial compensation than the residents of Namie Town, which led to some local resentment. In addition, her status changed from compulsory to voluntary due to her residential address registration. While living in the public housing, she started pulling out her hair and ended up losing most of it. In January 2018, she presented with her son at our clinic and was diagnosed as having severe cognitive disability and trichotillomania. Although she was not able to answer adequately most of the questions, she expressed a clear wish to return to her home in Namie Town. Despite her expressed desire to return home, her son judged she should not do so due to the absence of suitable medical and welfare facilities in Namie Town. She subsequently attended our clinic regularly. Neither sertraline (antidepressant) nor donepezil (dementia medication) stopped her hair pulling; only the presence of her son eased this behavior.

\section{Discussion}

An elderly female evacuee compelled to leave her home in a location threatened by a nuclear radiation, who had also lost her husband shortly after the Fukushima disaster, presented 
with dementia and displayed severe trichotillomania. Following stints in various temporary accommodations, the supportive relationships she had established with fellow evacuees disappeared after each relocation. ${ }^{7}$

Lifting of evacuation orders is obviously related to restored personal freedom and choice of residential location. ${ }^{8}$ However, the lifting of evacuation orders has varying impacts on evacuees. Japanese government policies focus on rapidly rebuilding disaster-hit communities based on past experiences, even though circumstances are completely different for nuclear accidents as compared to natural disasters such as earthquakes or tsunami. ${ }^{5}$ It is important to focus not only on the speed of recovering but also on the reality of returning home. As Maly pointed out, being able to return home, and the problems or benefits that may bring, are directly related to the cessation of valuable support mechanisms, such as temporary housing provision and compensation payments. ${ }^{5}$ The health of returnees could improve after returning home, or it may worsen, depending on variable circumstances. ${ }^{3}$ The mental health of vulnerable populations, such as the elderly, is particularly at risk, especially so if they are prevented from returning home against their wishes and if there are no family or community support networks available. It is thus not surprising that suicide rates in local populations increased following the lifting of evacuation orders in Fukushima. ${ }^{9}$

As already mentioned, evacuees might have difficulty establishing relationships with their neighbors for various reasons, resulting in extra stress and mental health decline. In this case, it appears that the lack or absence of close family members, in addition to the loss of support networks established in temporary housing, seriously compromised our patient's mental health. Hori et al reported the importance of evacuees creating stable and comfort new relationships following the 2011 triple disaster. ${ }^{10}$ Another report confirmed that social support and neighbor ties have been important for safeguarding the mental health of residents in the aftermath of the Fukushima disaster. ${ }^{11}$ Sekiguchi et al reported that social isolation worsened among people who moved to newly built permanent housing from prefabricated temporary housing, but did not worsen among people who remained in prefabricated temporary housing. ${ }^{7}$ Prefabricated housing comprised interim, relatively insubstantial structures that were comparatively uncomfortable or irritating for occupants because of noise, inadequate air conditioning, and other factors. However, they have the advantage that "psychological distance" between neighbors is reduced, as all occupants face the same basic predicament. In comparison, rebuilt housing stock re-establishes any physical or mental barriers between neighbors that may have existed previously-barriers and isolation that may multiply or increase in the post-disaster environment. This case highlighted the necessity for deeper understanding of the complex and interrelated factors affecting evacuees.
In summary, lifting of evacuation orders is important, allowing individuals to return home and attempt to rebuild their lives and livelihoods. However, depending on the circumstances and personal characteristics, returning home can either improve or harm the physical and mental health of evacuees. With respect to vulnerable groups, especially the elderly, the latter would appear more likely. This is because their loss is comparatively greater, with age-related physical decline, lost support networks, inadequate infrastructure, and possibly dangerous environments making their future prospects somewhat bleak. All of these interrelated factors need to be carefully considered and quantified in order to ensure that future postdisaster policies and strategies are best suited to safeguard or create optimum improvements in both physical and mental health.

\section{About the Authors}

Hori Mental Clinic, Minamisoma, Fukushima, Japan (Dr Hori); Department of Disaster and Comprehensive Medicine, Fukushima Medical University School of Medicine, Fukushima, Fukushima, Japan (Dr Hori); Research Center for Community Health, Minamisoma Municipal General Hospital, Minamisoma, Fukushima, Japan (Drs Ozaki, Tsubokura); Department of Breast Surgery, Jyoban Hospital of Tokiwa Foundation, Iwaki, Fukushima, Japan (Dr Ozaki); Department of Health Risk Communication, Fukushima Medical University School of Medicine, Fukushima, Fukushima, Japan (Dr Murakami) and Department of Radiation Health Management, Fukushima Medical University School of Medicine, Fukushima, Fukushima, Japan (Dr Tsubokura).

Correspondence and reprint requests to Arinobu Hori, MD, PhD, Hori Mental Clinic, 106 Gozen-no-uchi, Kashima, Kashima-ku, Minamisoma, Fukushima 979-2335, Japan (e-mail: arinobu.h@gmail.com)

\section{Informed Consent Statement}

Due to the patient's cognitive problems, consent for publication of this case report was given by her son.

\section{Conflict of Interest Statement}

Akihiko Ozaki receives personal fees from MNES Inc., unrelated to the submitted work. Other authors have no conflicts of interest to declare.

\section{List of Abbreviations}

FDNPS Fukushima Daiichi Nuclear Power Station

GEJE the Great East Japan Earthquake

\section{References}

1. The National Diet of Japan. Local Government of Namie Town. The official report of The Fukushima Nuclear Accident Independent Investigation Commission. https:/www.nirs.org/wp-content/uploads/ fukushima/naiic_report.pdf. Accessed January 23, 2019.

2. Oe M, Maeda M, Nagai M, et al. Predictors of severe psychological distress trajectory after nuclear disaster: evidence from Fukushima Health Management Survey. BMJ Open. 2016;6(10):e013400.

3. Murakami M, Takebayashi Y, Tsubokura M. Lower psychological distress levels among returnees compared with evacuees after the Fukushima nuclear accident. Tohoku J Exp Med. 2019;247(1):13-17. 
4. Local government of Fukushima prefecture. About extension of provision period of temporary housing for evacuees of the Great East Japan Earthquake. https://www.pref.fukushima.lg.jp/sec/11050b/kyouyo.html (inJapanese). Accessed January 23, 2020.

5. Maly E. Housing recovery and displacement from Fukushima: Five years post-nuclear meltdown. In: Santiago-Fandino V, Sato S, Maki N, et al, eds. The 2011 Japan Earthquake and Tsunami: Reconstruction and Restoration. Cham, Switzerland: Springer International Publishing; 2018:205-225.

6. Local Government of Namie Town. Present state of Namie Town. https:// www.town.namie.fukushima.jp/(inJapanese). Accessed January 23, 2020.

7. Sekiguchi T, Hagiwara Y, Sugawara Y, et al. Moving from prefabricated temporary housing to public reconstruction housing and social isolation after the Great East Japan Earthquake: a longitudinal study using propensity score matching. BMJ Open. 2019;9:e026354corr1.
8. Murankami M. Risk analysis as regulatory science: toward the establishment of standards. Radiat Prot Dosimetry. 2016;171(1):156-162.

9. Orui M, Kuroda Y, Yasumura S. Suicide rates and mental health measures after the lifting of the evacuation orders following the Fukushima Daiichi Nuclear Power Plant accident: A practical report developed in collaboration with the local municipality. Nihon Koshu Eisei Zasshi. 2019;66(8):407-416 [In Japanese]

10. Hori A, Morita T, Yoshida I, Tsubokura, M. Enhancement of PTSD treatment through social support in Idobata-Nagaya community housing after Fukushima's triple disaster. BMJ Case Rep. 2018;2018:bcr2018224935.

11. Midorikawa-Inomata $A$, Inoue $M$, Ishiguro $A$, et al. Associations Between Social Support and Subjective Symptoms in Disaster-Stricken Ishinomaki, Japan. Disaster Med Public Health Prep. In press. doi: 10. 1017/dmp.2019.121 